\title{
Production of Risk Classification Map for the Area Vulnerable To Mosquito-Transmitted Diseases, Suez Canal Zone
}

\author{
Ahmed M. El-Zeiny ${ }^{1}$, Asmaa M. El-Hefni ${ }^{2}$ and Mohamed M. Sowilem ${ }^{3}$ \\ ${ }^{1}$ Researcher, Environmental Studies and Land Use Division, National Authority for Remote Sensing and Space \\ Sciences (NARSS), Cairo, Egypt \\ ${ }^{2}$ Environment Studies Specialist, Environmental Studies and Land Use Division, National Authority for Remote \\ Sensing and Space Sciences (NARSS), Cairo, Egypt \\ ${ }^{3}$ Researchers, Environmental Studies and Land Use Division, National Authority for Remote Sensing and Space \\ Sciences (NARSS), Cairo, Egypt \\ ${ }^{1}$ Corresponding Author: aelzeny@ narss.sci.eg \& narss.ahmed@gmail.com \\ Tel. Number: +201007737052
}

\begin{abstract}
Suez Canal area is characterized by a unique nature therefore various species of mosquitoes are spread in the area. Present paper aims at mapping and classifying the area under environmental risk of mosquito proliferation and diseases transmission at Suez.Canal Zone using Landsat OLI data and GIS. To fulfil this objective, 6 field trips in the period from Nov.2014 to Apr.2016, were conducted to collect mosquito larvae and characterize breeding sites. Six calibrated Landsat-8 images were processed to characterize mosquitoes breeding sites and therefore map the area under environmental risk of mosquito proliferation. Considering the degree of mosquito proliferation, the study area was categorized into four levels of risk; high risk, risk, vulnerable and non-infected. Results of surveys showed that the main vector of Filarasis (Culex pipiens) was the most abundant species in Suez Canal Zone. The produced risk map showed that the total high risk area occupies $59.16 \mathrm{~km}^{2}(1 \%)$, risk area $2026.37 \mathrm{~km}^{2}(27 \%)$, vulnerable $497.5 \mathrm{~km}^{2}(7 \%)$ and non-infected $4940.43 \mathrm{~km}^{2}(65 \%)$ throughout Suez Canal Zone. Majority of the study area is located in the non-infected area which is concentrated in eastern and western deserts which are not inhabited. The high percent of the infected area is concentrated in several parts of Ismailia Governorate. The produced risk map is necessary requirement for decision makers to initiate mosquito control strategies and management programs. To assess the produced map, more than 120 different localities were visited. It could be concluded that Landsat-8 data and GIS techniques have proved high efficiency in mapping and classifying the area under risk of mosquito spread out particularly in inaccessible regions.
\end{abstract}

Keywords: mosquito, environmental risk, remote sensing, GIS, Suez Canal zone

\section{Introduction}

Mosquitoes have a greater importance in terms of major public health problems, approximately one million people died because of mosquito-borne diseases and about 247 million people become ill in tropical and subtropical areas of the world as reported by the World Health Organization (Guruprasad et al., 2014). Such diseases are Malaria, Lymphatic Filariasis, Yellow Fever, Encephalitis and Rift Valley Fever (Anosike et al., 2007). Different mosquito species belonging to genera Culex, Aedes and Anopheles serves as significant vectors of several serious diseases (Weaver and Reisen, 2010; Kilpatrick, 2011). This is arisen as a result of their abundance, mosquitoes' ability to carry disease-causing pathogens, recurrent infection and diversity (Njabo et al., 2013). Furthermore, mosquito bites can cause a substantial annoyance for humans and mammals. Severe annoyance can have adverse economic consequences (Connelly and Carlson, 2009).

Egypt is currently witnessing a number of mega projects, along the axis of Suez Canal, that aim to expand agricultural lands as well as logistics services, ease population pressures on the narrow Delta and create new job opportunities. These projects induce changes in land use/land cover which consequently have a great effect on the receiving environment and its biological components, including mosquito vectors of diseases. Such ecological disturbances may create suitable habitats for mosquito disease vectors allowing for their distribution into the project areas. All of these factors may generate health risks from emerging or re-emerging vector-borne 
diseases that would impact the integrity of development projects that ultimately aim for the prosperity of the Egyptian people (Hassan et al., 1999; Hassan, 2001; Hassan and Onsi, 2004; Hassan et al., 2004 and AbdelHamid et al., 2011).

On the other hand, integration between remote sensing and geographical information systems (GIS) can be used as rapid and accurate tools for the determination of some environmental factors affecting mosquito's proliferation. Moreover, they could successfully be utilized to predict the habitat suitability, which can help in designing optimal mosquito vector control strategies based on precise spatial/temporal information database. Consequently, most of the developed countries are applying these systems to form their own policy levels to mitigate the mosquito problem. Furthermore, geospatial mapping offers the potential to identify larval habitats on a large geographic area that is difficult or impossible for using field survey. Remote sensing and GIS have greatly expanded opportunities for data collection, integration, analysis, modeling and map production (Hayes et al., 1985; Washino and Wood, 1994; Hassan et al., 2003; Hanafi-Bojd, 2012; Sowilem, 2014; El-Zeiny et al., 2016).

There is a difficulty for accessing Suez Canal Zone for research studies as it requires special permissions which make it urgent to conduct more focused studies. Therefore, present study aims to utilize remotely sensed data, represented in Landsat images, and GIS techniques for detecting and classifying the area under environmental risk of mosquito proliferation at Suez Canal Zone.

\section{Materials and Methods}

\subsection{Studied Area and Field Survey}

The study area, representing in the western bank of the Suez Canal from Port Said on the northern extremity to Suez, includes three governorates; Port Said, Ismailia and Suez. It occupies an area of $7523.008 \mathrm{~km}^{2}$ and lies between latitude $29^{\circ} 30^{\prime} \mathrm{N}$ to $31^{\circ} 30^{\prime} \mathrm{N}$ and longitude $32^{\circ} 10^{\prime} \mathrm{E}$ to $32^{\circ} 40^{\prime} \mathrm{E}$. It is bordered from the north by Mediterranean Sea, west and south by eastern desert, and from the northern east by a part Sinai Peninsula. The direction of strong winds (wind speed over $10 \mathrm{~m} \mathrm{~s}^{-1}$ ) is generally between 240 and $360^{\circ}$ from North at Port Said (about $65 \%$ of the time), and between 330 and $360^{\circ}$ from North at Suez (about $50 \%$ of the time) (Abril and Abdel-Aal, 2000; El-Zeiny et al., 2016).

Initially, mosquito reproduction is successful only if larval habitats stay stagnant for a period equivalent to development of immature stages (Barros et al., 2011). Therefore, seepage from the Suez Canal as well as some irrigation and drainage branches accounted from most of the breeding sites positive for mosquitoes' larvae. During the study period (i.e. 2014-2016), more than 120 different localities were surveyed and monitored along Suez Canal Area, from Port Said Governorate to El-Ain El-Sokhna (i.e. South of Suez Governorate) as shown in Figure 1. From these sites, mosquitoes larvae were collected by dipping, using small ladle with a wooden handle, from small stagnant water bodies including; irrigated fields, drainage canals, sewage, sabkha land, cesspools, cesspits and from seepage areas. A total number of six field trips were mainly carried out to identify the characteristics of mosquito breeding sites as well as to ascertain the results obtained.

\subsection{Satellite Imageries Acquisition, Processing and GIS Analyses}

Space-borne multispectral Landsat8-OLI images were freely acquired from http://glovis.usgs.gov/. Six different time series images were downloaded and used in this study, covering the period 2014-2016 (Nov. 2014, Jan. 2015, Apr. 2015, Oct. 2015, Feb. 2016 and Apr. 2016). The study area is located within two different scenes (i.e. path 176, rows 38 and 39) and downloaded as raw data (i.e. digital number; DN). Before the data were analyzed, it was necessary perform pre-processing to normalize the data as well as to remove atmospheric effects and noise. For this purpose, ENVI V5.1 was used. A georeferenced mosaic was obtained and resized to crop the study area. To determine the best predictor of habitat type; Normalized difference Vegetation Index (NDVI), Normalized Difference Moisture Index (NDMI) and Land surface temperature (LST) were calculated according to Liang (2004) and Duran (2015).

Based on the corresponding values of NDVI, NDMI and LST at mosquito proliferation sites, these parameters were used as input criteria in a weighted overlay GIS model to predict mosquito breeding habitat in the whole Suez Canal zone (El-Zeiny et al., 2016). The predicted area was then classified considering the risk level into 4 classes. Class 1: High risk area represents mosquito habitat prediction at urban areas where urbanization facilitates the proliferation of different mosquito species that most often transmit pathogens to 
humans. Class 2: Risk area, a radius of two kilometers around the urban area served to determine the areas at risk of mosquito proliferation. Class 3: Vulnerable areas represent the areas which are environmentally suitable for mosquito breeding. Class 4: Non-infected which represent the area secured from mosquito borne-diseases.

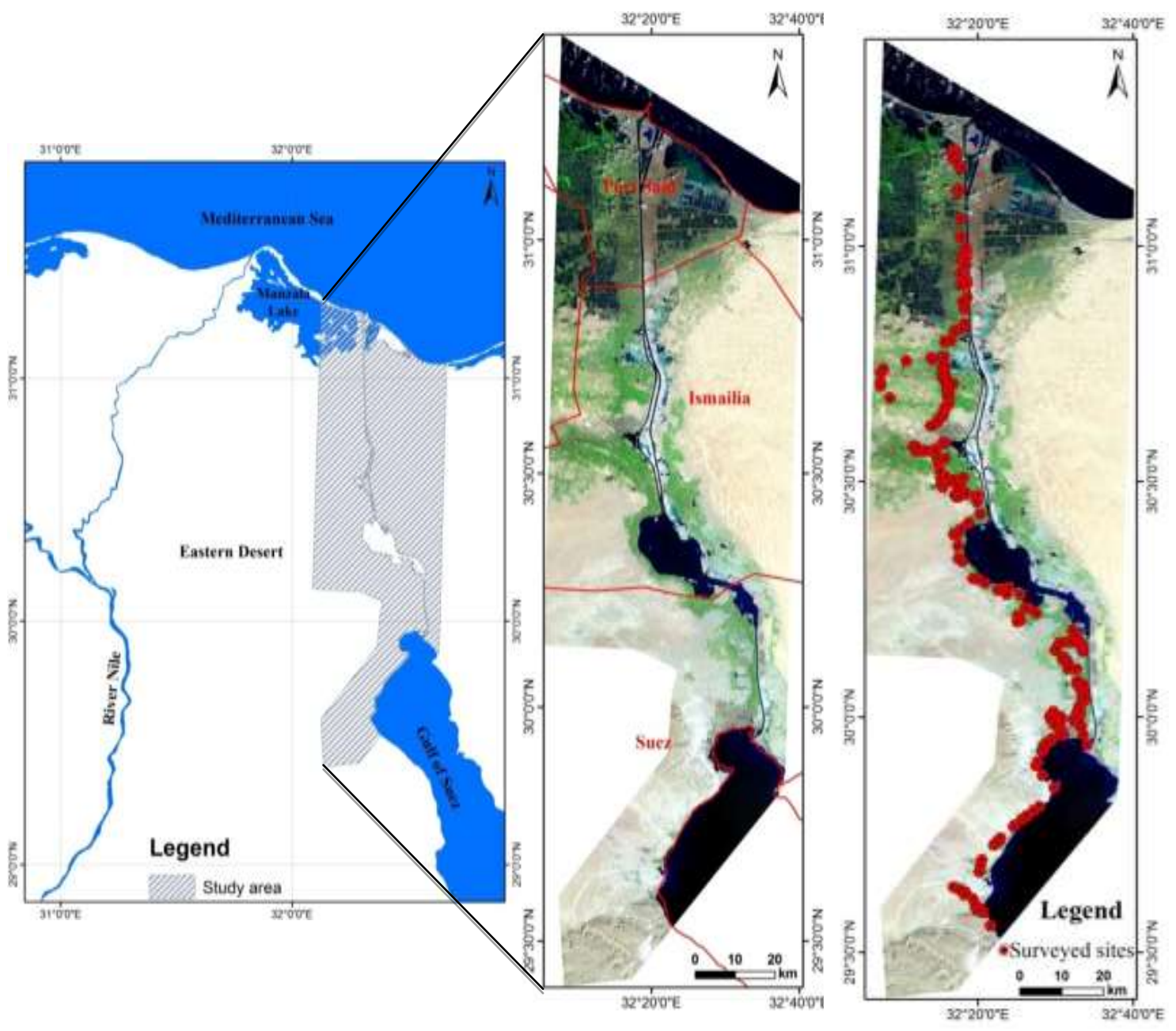

Fig. 1: Location map of the study area, right image represents surveyed sites

\section{Results and discussions}

\subsection{Mosquito larval abundance, medical importance and habitat characteristics}

Survey showed that Culex pipiens was the most abundant species in the study area (65.22\%) and widespread in most localities which are similar to the previous observations of El-Said and Kenawy (1983), Bahgat et al., (2004) and Abdel-Hamid et al. (2011). Ochlerotatus detritus, Culex perexiguus, Culex pusillus and Culiseta longiareolata recorded $13.86 \%, 10.59 \%, 7.2 \%$ and $1.32 \%$ respectively. Anopheles tenebrosus and Ochlerotatus caspius reported relatively same abundance; $0.69 \%$ and $0.68 \%$, respectively. In Egypt, Culicine mosquitoes mainly $C x$. pipiens and $C x$. perexiguus are the main vector disease of human filariasis (Gad et al., 1987). Oc. caspius has been incriminated to transmit Rift valley fever virus during 1977 \& 1993 epidemics (Gad et al., 1987; Turell et al., 1996).

Mosquitoes prefer an environment with certain resources (food, shelter, favorable temperature and suitable humidity) in sufficient quantity and at appropriate time for survival and development (Romoser and Stoffolano, 1998). Corresponding levels of NDVI, NDMI and LST at mosquito breeding sites were utilized to represent the environmental characteristics of mosquito habitat at Suez Canal Zone. NDVI at mosquito breeding sites was located within 0.1-0.22 which confirms the importance of vegetation, even sparse, for mosquito breeding, as shelter and feeding source, where most sites recorded positive values of NDVI (El-Zeiny et al., 2016. The type 
of vegetation which surrounds the breeding sites provides potential resting, sugar feeding supplies for adult mosquitoes and protection from climatic conditions. It may also be necessary in determining the abundance of mosquitoes related with the breeding site (Beck et al., 1994). Mean values of NDMI, at mosquito proliferation sites, recorded positive values $(0.01-0.07)$ which indicates the necessary of moisture for mosquito breeding. Optimum temperature for mosquito proliferation usually range from 27 to $37^{\circ} \mathrm{C}$ however it could survive at temperature $40^{\circ} \mathrm{C}$ or more as reported in Suez Canal zone at Oct. 2015. Temperature has an effect on both the vector and the parasite. For the vector, it affects the juvenile stages (egg, larvae, pupae) development rates, the length of the gonotrophic cycle and survivorship of both juvenile and adult stages with an optimal temperature and upper and lower lethal boundaries. For the parasite, it effects the extrinsic incubation period (Lactin et al., 1995).

\subsection{Risk area prediction and classification}

Based on the previous characteristics, area vulnerable to environmental hazard of mosquito proliferation was predicted. The predicted area was categorized into four different classes; high risk, risk, vulnerable area and nonpredicted to mosquito breeding according to risk degree of disease transmission. Prediction at residential areas represents class 1 which is the highly subjected areas to mosquito proliferation and spread of transmitted diseases. Zones around the infected residential area represent class 2, which is the area at risk of mosquito proliferation but lower in hazard than class 1 . On the other hand, areas that are environmentally and climatically suitable for mosquito breeding represent class 3 which are the areas vulnerable to mosquito breeding and infection probability (Figure 2). Class 4 is the rest area which is considered the non-infected zone where there's no possibility of mosquito breeding and/or transmitted diseases due to the inappropriate conditions to mosquito breeding. A risk area classification map was generated which have categorized the area of study in relation with hazards of mosquito breeding and vector-borne disease. This map is considered the first developed map for Suez Canal Zone which has been created based on 2 years of work (Figure 2). The total high risk area, throughout Suez Canal Zone, occupies $59.16 \mathrm{~km}^{2}(1 \%)$, risk area $2026.37 \mathrm{~km}^{2}(27 \%)$, vulnerable $497.5 \mathrm{~km}^{2}(7 \%)$ and noninfected $4940.43 \mathrm{~km}^{2}(65 \%)$. Majority of the study area is located in the non-infected area which is concentrated in eastern and western deserts which are not inhabited. The high percent of the infected area is concentrated in several parts of Ismailia Governorate. Actually, such map is very necessary for decision makers. It could help to initiate mosquito control strategies and management programs starting by the high risk area and ending by the vulnerable area. Furthermore, geographic locations of the expected area are well defined which facilitate the reachability to the infected sites. To ascertain the produced map and test the accuracy of the obtained classes, more than 120 different sites were visited. The overall accuracy of the risk area classification map reached more than $80 \%$ in predicting the area under environmental risk of mosquito proliferation.

\section{Conclusion}

In this study, space-borne technology integrated with field surveys were used to detect the area under risk of mosquito proliferation at Suez Canal Zone. GIS environment was successfully employed for classifying the area under risk of mosquito proliferation and diseases transmission. Landsat images (OLI) were processed to characterize mosquito breeding sites which were then employed to define and detect mosquito habitats. NDVI, NDMI and LST were selected to describe the environmental characteristics of mosquito breeding habitats. The study produced, for the first time, a classified image for the area under environmental risk of mosquito proliferation. At Suez canal Zone, four main levels of risk to mosquito breeding were identified; high risk area $59.16 \mathrm{~km}^{2}(1 \%)$, risk area $2026.37 \mathrm{~km}^{2}(27 \%)$, vulnerable $497.5 \mathrm{~km}^{2}(7 \%)$ and non-infected $4940.43 \mathrm{~km}^{2}$ (65\%). The study concluded that Landsat data and GIS techniques have provided the necessary information and/or tools for mosquito proliferation studies. Also they could successfully be utilized for producing and classifying the mosquito risk areas at a large scale which is not possible by conventional methods. 


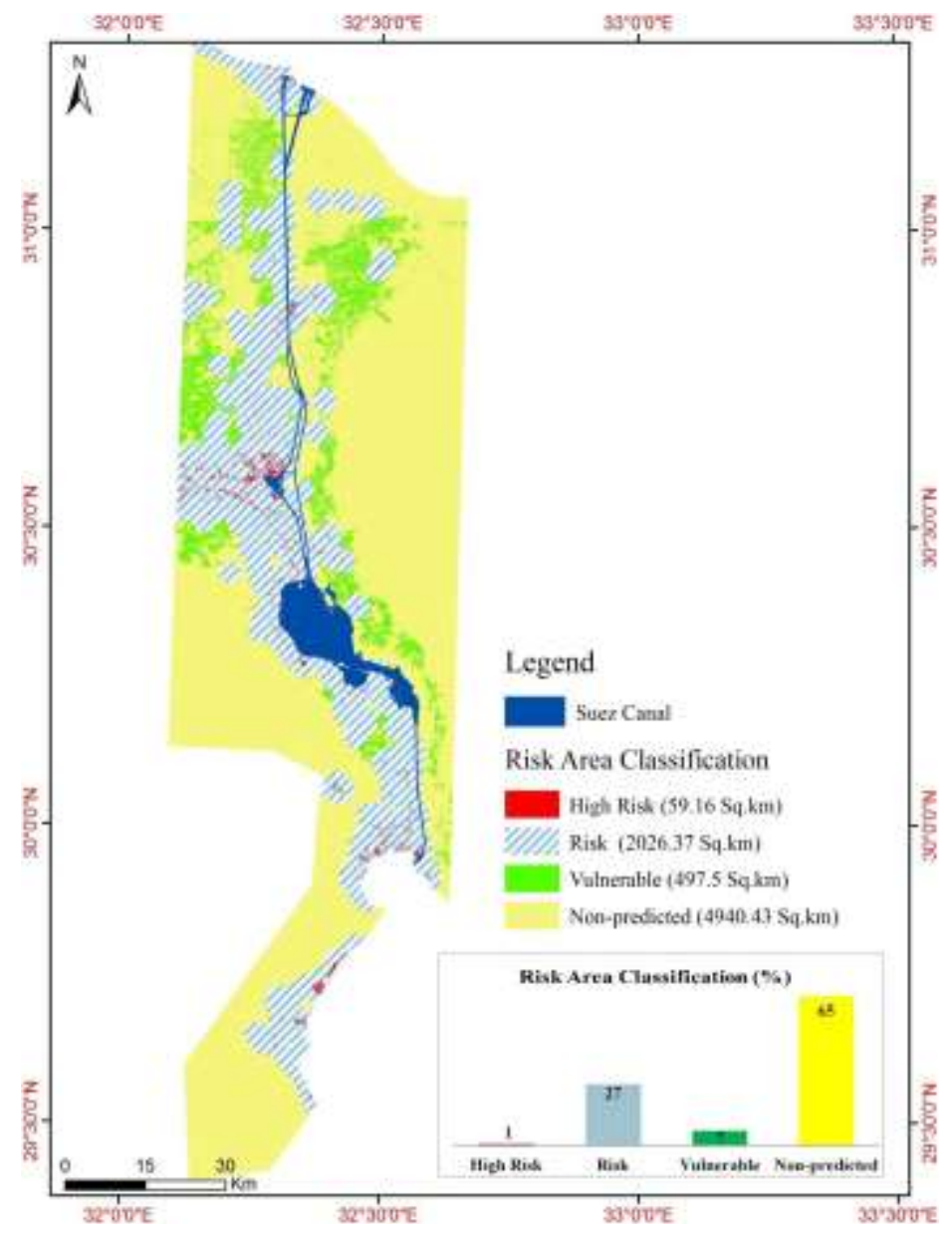

Fig. 2: Risk Area Classification map for Mosquito Proliferation

\section{Acknowledgment}

Appreciations to the National Authority for Remote Sensing and Space Sciences for sponsoring R\&D project titled "Modeling spatial/ temporal distribution of mosquito breeding habitats and monitoring environmental factors associated with the proliferation in Suez Canal Zone, using remote sensing and GIS" (2014-2016) through which the paper data was acquired and to the USGS for supporting Landsat images to this research. Thanks are extended to Dr. Hazem Taha, NIOF for his kind help to analyze O.M. in water.

\section{References}

[1] A. Hanafi-Bojd, H. Vatandoost, M. A. Oshaghi, Z. Charrahy, A. A. Haghdoost, M. M. Sedaghat, F. Abedi, M. Soltani and A. Raeisi (2012). Larval habitats and biodiversity of anopheline mosquitoes (Diptera: Culicidae) in a malarious area of southern Iran. J Vector Borne Dis 49: pp. 91-100.

[2] M. Gad, M. M. Hassan, S. EI-Said, M. L. Moussa and O. L. Wood (1987). Rift Valley fever transmission by different Egyptian mosquito species. Trans. Roy. Soc. Trop. Med. Hyg. 81:694-8.

[3] M. Kilpatrick (2011). Globalization land use and the invasion of West Nile virus. Sci. 334(6054):323-327.

[4] N. Hassan (2001). Environmental change and associated mosquito ecology along the gulf of Suez, Egypt. J. Egypt, Acad. Soc. Environ. Develop. (A-Entomology), 1(1):53-71.

[5] N. Hassan and H. M. Onsi (2004). Remote sensing as a tool for mapping mosquito-breeding habitats and associated health risk to assist control efforts and development plans: A case study in Wadi El Natroun, Egypt. J. Egypt. Soc. Parasitol., 34(2): 367-382.

[6] Tran, C. Ippoliti, T. Balenghien, A. Conte, M. Gely, P. Calistri, M. Goffredo, T. Baldet and V. Chevalier (2013). A geographical information system-based multicriteria evaluation to map areas at risk for Rift Valley fever vector-borne transmission in Italy. Transbound Emerg Dis.60: 14-23. 
[7] A.A. Amusan, C.F. Mafiana, A.B. Idowu and G.O. Ola-tunde (2005). Sampling mosquitoes with CDC light traps in rice field and plantation communities in Ogun State, Nigeria. Tanzania Health Research Bulletin7, 111-116.

[8] A.El-Zeiny, A. El-Hefni and M. Sowilem (2016). Geospatial techniques for environmental modeling of mosquito breeding habitats at Suez Canal Zone, Egypt. Egyptian Journal of Remote Sensing and Space Sciences. In press: http://dx.doi.org/10.1016/j.ejrs.2016.11.009

[9] A.N. Hassan, H. A. Kasem and B. M. El Sawaf (1999). Species composition and abundance of sand flies at natural desert and modified agricultural lands at Nekhel, Sinai, Egypt, j. Egypt-German Soc. Zool. 28(E):37-47.

[10] A.N. Hassan, H. E. El Ashry and M. M. Sowilem (2004). Mosquito fauna of new water resources and agricultural development projects in Egypt: El Salam Canal and Toshka. J. Environ. Scie. 9(3): 787-800.

[11] A.N. Hassan, M.A. Kenawy, H. Kamal, A.A. Abdel Sattar, and M.M. Sowilem (2003). GIS-based prediction of malaria risk in Egypt. La Revue de Santé de la Méditerranée orientale, Vol. 9, No 4, p. 548-558.

[12] R. Laurence (1967). Elephantiasis in Greece, Rome and the Queen of Punt. Trans. Roy. Sco. Trop. Med. Hyg., 61: 612-613.

[13] Romoser and R.S. Stofollano (1998). The Science of Entomology. MCGrew Hall, London pp 328.

[14] Baz, N. (1946). Distribution of filariasis in Egypt. J. Roy. Med. Ass. 21 (7, 8): 280 - 286.

[15] Duran (2015). Drought and vegetation analysis in Tarsus River Basin (Southern Turkey) using GIS and Remote Sensing data. International Journal of Human Sciences, Volume: 12 Issue: 2

[16] C.R. Connelly and D.B. Carlson (2009). Florida Coordinating Council on mosquito control. Florida mosquito control: The state of the mission as defined by mosquito controllers, regulators, and environmental managers. Vero Beach, Florida: University of Florida, Institute of Food and Agricultural. FDA CS \#012902, University of Florida Project \#00068572.

[17] D.J. Lactin, N.J Holliday, D.L Johnson, and R. Craigen (1995). Improved rate model of temperature-dependant development arthropods. Environment Entomology 24: 68-75.

[18] S., Barros, M. E. Arruda, H.C. Gurgel and N.A. Honorio (2011). Spatial clustering and longitudinal variation of Anopheles darling (Diptera: Culicidae) larvae in a river of the Amazon: The importance of the forest fringe and of obstructions to flow in frontier malaria. Bulletin of Entomological Research. 101(6): 643-58.

[19] H.Hoogstraal, J. M. Meegan, G. M. Khalil, and F. K. Adham (1979). The Rift Valley fever epizootic in Egypt 1977-78. 2. Ecological and entomological studies. Trans. R. Soc. Trop. Med. Hyg. 73: 624-9.

[20] I.M. Bahgat, G.A. El Kadi, M.M. Sowilem and B.M. El Sawaf (2004). Host-feeding patterns of Culex pipiens (Diptera: Culicidae) in a village in Qalubiya Governorate and in a new settlement in Ismailia Governorate. Bull Ent Soc Egypt. 81:77-84.

[21] J. Anosike, B. Nwoke, A. Okere, E. Oku, J. Asor, I. Emmy-Egbe and D. Adimike (2007). Epidemiology of tree-hole breeding mosquitoes in the tropical rainforest of Imo State, South-east Nigeria. Ann. Agric. Environ. Med., 14: 31-38.

[22] J. M. Abril and M. M. Abdel-Aal (2000). A modeling study on hydrodynamics and pollutant dispersion in the Suez Canal. Ecological Modelling, 128, pp 1-17.

[23] K. Y. Njabo, T. B. Smith and E. Yohannes (2013). Feeding habits of culicine mosquitoes in the Cameroon lowland forests based on stable isotopes and blood meal analyses. J Parasit Vector Biol. 5(1):6-12.

[24] K.M Knio, N. Markarian, A. Kassis and N. Nuwayri-Salti (2005). A two-year survey on mosquitoes of Lebanon. Parasite, 12:229-235.

[25] L.R. Beck, M.H. Rodriguez, S.W. Dister, A.D. Rodriguez, R.K. Washino and D.R. Roberts, et al. (1997). Assessment of a remote sensing -based model for predicting malaria transmission risk in villages of Chiapas, Mexico. Am J Trop Med Hyg; 56: 99-106.

[26] M. M. Sowilem (2014). Defining spatial distribution of mosquito breeding sites and areas under risk using remote sensing - GIS integration. J. Biotechnol Biomater, Volume 3, Issue 5, p. 76.

[27] M.A. Barber and J.B. Rice (1937). A survey of malaria in Egypt. Am. J. Trop. Med. Hyg. 17:413 -36.

[28] M.A. Kenawy (1988). Anopheline mosquitoes (Diptera: Culicidae) as malaria carriers in A.R. Egypt (History and present status). J. Egypt. Publ. Hlth. Assoc. 63:67-85.

[29] M.J. Turell, S.M. Presley, A.M. Gad, S.E. Cope, D.J. Dohm, et al. (1996). Vector competence of Egyptian mosquitoes for Rift Valley fever virus. Am. J. Trop. Med. Hyg. 54:136-9.

[30] Meegan, J., Hoogstraal, H. and Moussa, M. (1979). An epizootic of Rift Valley fever in Egypt in 1977. Vet Rec 105: $124-125$.

[31] N.H. Ghoneim and G.T. Woods (1983). Rift Valley fever and its epidemiology in Egypt. J. Med. 14:55-79.

[32] R. K. Washino and B. L. Wood (1994). Application of remote sensing to vector arthropod surveillance and control. Am. J. Trop. Med. Hyg. 50 (6 Suppl): 134-144.

[33] R. O. Hayes, E. L. Maxwell, C. J. Mitchell and T. L. Woodzick (1985). Detection, identification and classification of mosquito larval habitats using remote sensing scanners in earth orbiting satellites. Bull. World Health Organ. 63: 361 374. 
[34] S. El-Said and M.A. Kenawy (1983a). Geographical distribution of mosquitoes in Egypt, Journal of the Egyptian Public Health Association., 58: 46-76

[35] S. I. Hay, R. W. Snow and D. J. Rogers (1998). Predicting malaria seasons in Kenya using multi-temporal meteorological satellite sensor data, Transactions of the Royal Society of Tropical Medicine and Hygiene, 92:12-20.

[36] S. Kalluri, P. Gilruth, D. Rogers, and M. Szczur (2007). Surveillance of arthropod vector-borne infectious diseases using remote sensing techniques: a review. PLoS Pathog. 3:e116.

[37] S. Liang (2004). Quantitative Remote Sensing of Land Surfaces. Wiley, New Jersey, 479-501.

[38] S.C. Weaver and W.K. Reisen (2010). Present and future arboviral threats. Antivir Res 85:328-345.

[39] S.E. Ammar, M.A. Kenawy, H.A. Abd El Rahman, A.M. Gad and A.F. Hamed (2012). Ecology of the mosquito larvae in urban environments of Cairo Governorate, Egypt, Journal of the Egyptian Society of Parasitology , 42: 191202.

[40] Y.H. Al-Khalili, A. Katbeh-Bader and Z. H. Mohsen (1999). Siphon index of Culex pipiens larvae collected from different biogeographical provinces in Jordan. Zool Middle East, 17, pp71-76.

[41] Y.M. Abdel-Hamid, M.I. Soliman and M.A. Kenawy (2011). Mosquitoes (Diptera: Culicidae) in relation to the risk of disease transmission in El Ismailia Governorate, Egypt, Journal of the Egyptian Society of Parasitology , 41: 347-356

[42] Z.S. Amr, Y. Al-Khalili and A. Arbaji (1997). Larval mosquitoes collected from northern Jordan and the Jordan Valley.J Am Mosquito Contr, 13: 375-378. 